\title{
The impact of dynamic price variability on revenue maximization
}

\author{
Graziano Abrate ${ }^{1}$, Juan Luis Nicolau², Giampaolo Viglia ${ }^{3}$
}

Keywords: Pricing; revenue management; intertemporal price discrimination; inventory control; price fairness; hotels.

${ }^{1}$ University of Piemonte Orientale "A. Avogadro", Department of Economics and Business, Via Perrone 18, 28100 Novara, Italy. Telephone: +39 (0)321 375 440. Email: graziano.abrate@ uniupo.it; corresponding author

${ }^{2}$ Virginia Tech Pamplin College of Business, Hospitality and Tourism Management, Blacksburg VA 24061, USA. Telephone: +1 540231 8426. Email: jnicolau@vt.edu

${ }^{3}$ University of Portsmouth, Department of Marketing and Sales, Portland Street, PO13DE, United Kingdom. Telephone: +44 0239284 4148. Email: giampaolo.viglia@port.ac.uk

\section{Highlights}

The paper offers a comprehensive analysis on the effect of dynamic price variability on revenue maximization

Measuring whether or not tourism players are applying the right extent of dynamic price variability

A new hedonic revenue model is applied to sample of 21687 hotel observations coming from 17 European cities

Tourism and hospitality players use dynamic price variability at sub-optimal levels 


\title{
THE IMPACT OF DYNAMIC PRICE VARIABILITY ON REVENUE MAXIMIZATION
}

\begin{abstract}
The objective of this article is to analyze the effect of dynamic price variability on revenue maximization. While dynamic pricing is a common practice in tourism, this is the first comprehensive study on the relationship between price variability and revenue maximization. Within the framework provided by the literature on intertemporal price discrimination, price fairness, inventory controls and organizational culture, this research proposes and applies a new hedonic revenue model on a sample of 21,687 observations. The findings suggest that higher dynamic price variability leads to higher hotel revenues. Strategic room unavailability and review rating also exert a clear positive revenue impact. Overall, the benefits from charging different prices for the same service (intertemporal price discrimination) and limiting the number of units available before the demand is known (inventory control) outweigh the potential negative effects of price unfairness and organizational culture. The paper concludes by providing actionable levers for hospitality managers.
\end{abstract}

Keywords: Pricing; revenue management; intertemporal price discrimination; inventory control; price fairness; organizational culture 


\section{Introduction}

The ability to set the right price at the right time is an important way of appropriating value and generating revenues. Dynamic pricing is the practice of integrating inter-temporal price variations over the booking horizon (McAfee and te Velde, 2006; Abrate, Fraquelli, and Viglia, 2012). Technologies which empower companies to change prices rapidly and efficiently are currently in the market and can be used for better management of prices and inventory, potentially leading to increased margins with minimal additional capital outlay (Melis and Piga, 2017). The diffusion of dynamic pricing is more profound for companies in the travel sector, where it is difficult to change capacity in the short term and where variable costs are relatively small. Since the mid 1980s, airlines, hotels and other firms operating in tourism industries pioneered many groundbreaking ecommerce applications by utilizing techniques to improve their pricing and inventory allocation decisions. Dynamic pricing is gaining popularity also in sharing economy accommodation platforms to enhance price positioning (Oskam, Van Der Rest and Telkamp, 2018; Xie and Kwok, 2017). With these automatized models, prices may frequently update depending on changing supply or demand conditions and these changes are consistent across customers. In addition, this term has also been recently used for personalized pricing strategies (Richards, Liaukonyte, and Streletskaya, 2016).

The revenue management literature has remained relatively silent on quantifying the dynamic pricing's effects over fixed-price policies. Anderson and Xie (2016) and Grewal et al. (2011) identified the impact of dynamic pricing models on performance as an interesting research issue, especially in light of the models' potential long-term effects on reference price. However, empirical studies on this topic are scarce, primarily due to the difficulty of obtaining empirical data both on prices and available inventory, endogeneity concerns, and the complexity of a problem that involves markets with multiple competitors. Initial exploratory studies are discordant on the effects of such 
strategies. Sweeting (2012) and Sen (2013) show that dynamic pricing might have a significant positive effect on performance while Gallego and van Ryzin (1994), supported by Xia, Monroe and Cox (2004), claim that fixed-price strategies lead to better performance. In addition, Kalnins (2016), thus recognizing that new technologies permit capitalizing on dynamic pricing, points out possible organizational culture issues, underlying also that "price-point movement cannot be costless" (p. 2,252). The consumer behavior literature adds to the conversation, stating that dynamic pricing might raise concern in terms of consumer price fairness perceptions (Haws and Bearden, 2004; Xia et al., 2004). Therefore, the impact of price variations on revenues is at a moot point, and given the widespread adoption of these techniques, there is the need for studies that assess its impact on revenue maximization (Anderson and Xie, 2010; Guillet and Mohammed, 2015).

The goal of this paper is to test the impact of dynamic price variability on revenues. We focus on "how fares evolve in time" and on the extent of inter-temporal price variation for the assessment of dynamic pricing (Abrate, Fraquelli, and Viglia, 2012). The underlying research question is whether or not - and by what extent - dynamic price variability (i.e., the magnitude of price variation over the time purchase window) has a positive impact in terms of revenue maximization. The chosen empirical context is the hospitality industry. Because hotel rooms are a perishable service, designing rates' temporal profile to maximize revenues is of paramount importance for the sector. To perform this analysis, we match data from two sources, online travel agencies (OTAs) and individual hotel performance data. During the consumer purchasing process, online travel agencies (OTAs) have become the most popular distribution channel for hotel rooms, with nearly $70 \%$ of rooms sold (Lee, Guillet and Law, 2013; Verhoef, Kannan and Inman, 2015). OTAs are successful because they offer hotels a significantly larger market size. OTAs operate through two different models: the merchant and the agent model. In the merchant model, the OTA purchases rooms from the hotel at a wholesale price and sells them at a profit to its customers. Therefore, the OTA shoulders the inventory risk of the unsold rooms. In the agency model, the OTA acts only as an 
agent in the transaction; it passes booked reservations and receives an agreed commission fee on each transaction. In this case, the hotel bears all the inventory risk but has a higher profit margin for each room. An example of a merchant model OTA is Orbitz while Booking.com operates only through an agent model (Ye, Zhang and Li, 2018). When the inventory and price responsibility is on single hotels, the impact of dynamic price variability on revenue maximization is measurable. Therefore, in this paper, we focus on the agent model.

Showing whether - and to what extent - dynamic price variability increases revenues, our findings offer clear practical implications for tourism and hospitality players. Theoretically, the paper contributes to the existing dynamic pricing literature in tourism and hospitality (Abrate and Viglia, 2016; Enz et al., 2016; Melis and Piga, 2017; Malasevska and Haugom, 2018, Oskam et al., 2018) by proposing and testing a hedonic revenue model, offering insights on the relationship between dynamic price variability and revenues. Our findings can be generalized to tourism and hospitality settings with fixed finite capacity which cannot be changed in the short term, like airline industry, car rental, ski lift and catering industry.

\section{Background}

Dynamic pricing strategies have been studied at least in four different streams of literature, $i$ ) intertemporal price discrimination, which suggests charging different prices over time to target consumers with different willingness to pay, ii) price fairness, which has mainly investigated the relation between price variations and perceived price fairness, iii) inventory controls, which has incorporated the presence of strategic consumers as a possible threat to the effectiveness of such strategies and iv) organizational culture, which might explain whether these strategies are implemented or not. In what follows we present the different approaches, discussing their prediction in terms of the effectiveness of different dynamic pricing strategies. 


\subsection{Intertemporal price discrimination}

Price discrimination is the practice of selling the same item at different prices. More specifically, price discrimination occurs when a firm charges different prices for "similar" products, with the same marginal cost, or in a wider definition, when the prices of two similar products are in different ratios to their marginal costs (Armstrong, 2006). Previous economics theoretical literature has shown that profitable price discrimination might be possible even in competitive markets (Dana, 1998). When the only difference in the sold items is the time of purchase, the theory distinguishes the case of intertemporal price discrimination (Stokey, 1979) and behavior-based price discrimination (Villas-Boas, 1999). Intertemporal price discrimination occurs when prices differ according to the time of purchase but, at a given time, are the same for all customers. Behaviorbased price discrimination implies charging different customers personalized price dynamics, according to their past purchase history (Caillaud and De Nijs, 2014). Technological tools have made easier for companies to apply these two sources of dynamic pricing strategies. In the case of non-durable goods such as airline tickets or hotel rooms, late bookers carry an increasing opportunity cost due to the risk of having unsold inventory (Lott and Roberts, 1991).

Some criteria for intertemporal price discrimination involve the degree of patience (Su, 2007) and the nature of the customer, business or leisure (Alderighi et al., 2016). For instance, Su (2007) considers a heterogeneous population of both myopic and strategic consumers. His model suggests that optimal price paths could involve either markups or down, depending on the degree of customer patience. In the tourism industry, it is more common to observe increasing price trends (Gaggero and Piga, 2011; Alderighi, Nicolini, and Piga, 2015). However, the opposite could also be profitable, even in the presence of full or partial refunds policies (or free cancellation). For instance, in the context of retailing, Cohen-Vernik and Pazgal (2017) propose a policy where the seller refunds a fraction (potentially greater than one) of any future price difference. Their study shows 
that the profitability does not necessarily depend on the premise that some consumers do not request the refund. Discounting is a widely use tactic to respond to competitive price positioning and benefit from elasticity of demand (Van Der Rest and Harris, 2008; Noone et al., 2013). However, there is extensive evidence showing that just using discounting does not help in the long run (Enz, Canina and Lomanno, 2004; Enz, Canina and Van Der Rest, 2016), unless the discounting structure is more sophisticated and shows non-stationary tendencies (Croes and Semrad, 2012).

If the theory generally supports the use of intertemporal price discrimination, only few empirical works provide a direct estimate of its impact on economic performance. Sweeting (2012) analyzed data from the secondary markets for Major League Baseball tickets and predicts that dynamic pricing increases the average seller's expected profit by 16 percent. Bilotkach, Gaggero and Piga (2015) utilized evidence from the case of Easyjet tickets and found that active dynamic pricing positively affects load factors in the airline industry. Other than papers which base themselves on a single league or company, the empirical literature has mainly focused on the relationship between market structure and price dispersion. Despite conventional wisdom which suggests competition should favor uniform prices, Bayer (2010) found that competition does not prevent successful intertemporal price discrimination. More specifically, competition is favorable in the case of "earlybird" discounting or when consumers with a low price valuation start searching earlier for cheap prices with respect to high-value consumers.

In sum, the intertemporal price discrimination literature suggests that dynamic price variations should boost revenues, even in competitive contexts.

\subsection{Price fairness}

Price changes are related to price fairness perceptions, and these judgments depend on the motive of the price change. For example, profit-driven price increases are considered more unfair when compared to cost-justified motives (Xia et al., 2004; Tarrahi, Eisend, and Dost, 2016). Even though 
dynamic pricing's concept stemmed from work in 1978 by Huppertz, Arenson and Evans, recently, due to the intensive application of dynamic pricing in online contexts, price fairness concerns have grown.

Customers can either make an explicit comparison of two or more actual product prices or an implicit comparison with an expected reference price perceived as fair (Thaler, 2008). When there are favorable conditions for dynamic pricing, price instability increases and reference prices become particularly relevant. Due to past purchases or contextual cues, customers become aware that they pay a different price for the same product and this increases the perception of price unfairness (Fosfuri, Giarratana, and Roca, 2015). A consumer would perceive non-uniform pricing as unfair and thus incur disutility if other consumers pay a lower price for a product from the same firm (Chen and Cui, 2013).

The development of price fairness perceptions ranges from characteristics of other customers buying the product, individual's past transactions and reasons behind price change, to general knowledge and beliefs about the seller's pricing strategies (Xia et al., 2004). This strand of consumer behavior literature concludes that dynamic pricing is harmful in terms of price unfairness perceptions, suggesting that consumers lower their reference prices and wait for markdowns before purchasing products (Xia et al., 2004; Karande and Magnini, 2011).

Although the literature above would suggest that dynamic pricing might damage performance, the literature is silent on the actual effects of price fairness on consumer behavior in tourism. However, stemming from Kimes (1994), there are now quite a few theoretical or experimental studies (Chen and Cui, 2013; Choi and Mattila, 2004; Heo and Lee, 2011; Viglia and Abrate, 2014; Viglia, Mauri, and Carricano, 2016) suggesting that, while consumers' unfairness perception because of dynamic pricing strategies have generally decreased over time, there are still some consumer segments which hold negative perceptions. Therefore, there is the need to investigate the actual revenue repercussions when customers perceive sellers' prices as unfair. Specific evidence from the 
hospitality industry suggests that price unfairness is detrimental in terms of consumer perceptions toward the hotel (Sahut et al., 2016).

In sum, the price fairness literature predicts that dynamic price variations should harm revenues, due to the role of perceived price unfairness.

\subsection{Inventory controls}

The term "inventory control" refers to all models and processes which sell the right amount of each item at any time. In the context of perishable goods, this implies limiting the number of available items, e.g., seats in an aircraft, rooms in a hotel etc., to ensure there will be available items till the end of the booking window (Weatherford and Bodily, 1992). Therefore, this pricing profile is designed before demand is known. Possible revisions of this profile can be classified as stochastic peak load pricing (Bilotkach et al., 2015). This latter practice is particularly important when the actual demand is much lower than expected and, in the absence of any rectifying intervention that shifts prices downward, many items would be unsold. Hayes and Ross (1998) and Stavins (2001) suggest a clear link between the strategies attributed to yield management and observed price dispersion. Stochastic yield management and dynamic pricing can be seen as synonymous, because they both identify changes to a prior pricing schedule (Bilotkach et al., 2015).

Theoretical papers predict a monotonically increase of prices (Dana, 1999; Deneckere and Peck, 2012). However, empirical observation in tourism has found that prices do not generally monotonically increase over time (Alderighi et al., 2015). The fixed capacity of perishable assets contexts is generally accompanied by widely fluctuating demand, which makes balancing availability and demand difficult.

Elmaghraby and Keskinocak (2003) embrace a dual categorization of customers, myopic and strategic. A myopic consumer makes a purchase if the price is below her valuation (reservation price), without considering future prices. Markets characterized by myopic consumers allow the 
seller to ignore detrimental effects of future price variations on current purchases. With perishable assets, as there is no opportunity for inventory replenishment, the selling horizon is independent over time. Therefore, quick price variations to match supply with uncertain demand mitigate the consequences of leftover inventory. Conversely, a strategic (or rational) consumer takes into account future path of prices when making purchasing decisions (Chen and Schwartz, 2008). A strategic consumer chooses not only whether to buy a product but when to buy it. This group of consumers will try to maximize expected utility by waiting for the first markdown to make purchases. With these consumers, dynamic pricing decisions of sellers are more complex, because the seller has to consider future and current prices.

Online tools now analyze price data to empower consumers to make informed decisions. An example of decision support systems in the hospitality environment is Tingo, a program that rebooks a hotel room for free if prices go down. Some theoretical models define the optimal behavior of strategic consumers with respect to dynamic pricing policies. For instance, Aviv and Pazgal (2008) study exogenously specified dynamic pricing policy with the presence of forward-looking (strategic) consumers. Nonetheless, these stylized models do not present an empirical validation to actually measure the behavior of customers when facing dynamic prices strategies.

In sum, the inventory control literature conveys that dynamic price variations pay off in terms of revenues, but their effect might be weakened by the presence of strategic customers.

\subsection{Organizational culture}

The implementation of dynamic pricing requires an organizational structure that supports it (Aubke et al., 2014; Kalnins, 2016). In this sense, Dutta, Zbaracki and Bergen (2003) highlight the central role of social and human factors in the company's application of pricing strategies. More specifically, for the successful application of dynamic pricing, the two main elements - presented in Selmi and Dornier (2011) - are i) the presence of an appropriate IT infrastructure and ii) some 
training for hotel managers in order to overcome initial skepticism and enhance the understanding of revenue managers concepts. On the first point, nowadays the required IT infrastructure is minimal, thanks to price multipliers approaches (see Bayoumi et al. 2013) or modern online and cloud solutions that reduce the need to own a fully dedicated revenue management IT server (see, for instance, https://www.cloudbeds.com). On the second point, training and learning aspects remain a potential barrier (Van der Rest et al., 2018). Due to the complex interaction among internal organization's characteristics, its culture, the different functional areas (e.g., Sales and Finance) and the different environmental pressure (e.g., competition), there are still learning issues. Additionally, applying dynamic pricing with incomplete information is complex and requires quite advanced skills (Den Boer, 2015).

Organizational aspects are generally unobserved by the researcher and thus it is impossible to establish a direct causation between organizational issues and dynamic pricing implementation (Melis and Piga, 2017). However, the mere adoption of dynamic pricing in day-by-day operations would be a sign of limited organizational concerns toward the use of this pricing technique.

In sum, the propensity to engage in dynamic pricing - more than the exact variability of such price variations - should explain possible organizational issues in dynamic pricing adoption.

Figure 1 presents the conceptual framework graphically, showing the disagreement among the different streams. The empirical analysis investigates the impact of dynamic price variability on revenue maximization, unclosing which argument - positive or negative - prevail. 
[Insert Figure 1 here]

The whole theoretical discussion, with the opposing effects shown in Figure 1, leads to our main research question:

RQ: What is the impact of dynamic price variability on revenues? Are tourism players applying the right extent of dynamic price variability?

\section{Methodology}

The hedonic literature (Lancaster, 1966) provides a standard empirical setting for measuring the determinants of the value of a product. Using a revealed preference approach based on actual price data, this model infers consumers' perception of quality differentials. This technique has been widely used in a variety of valuation issues, ranging from housing (Harding, Rosenthal, and Sirmans, 2003) to more sensorial environments, such as wine evaluation (Combris, Lecocq, and Visser, 1997). The model is popular in the tourism and hospitality domain when assessing the determinants of price (see Falk, 2008; Rigall-I-Torrent, R., \& Fluvià, 2011; Ropero, 2011; Abrate \& Viglia, 2016) and revenue performance (see Hua and Yang, 2017).

Despite its diffusion, there is no evidence whether the pricing strategy itself can create value for the firm, as suggested by Dutta et al. (2003). The original formulation of the model considers a perfectly competitive setting where price provides a natural measure of the product's market value, and is thus the dependent variable. However, with the increasing complexity of pricing strategies and the diffusion of dynamic pricing, choosing a unique measure of price as a proxy for value has become more difficult. Even more so in the case of perishable assets, where unsold inventory must be accounted. This means that the use of a traditional hedonic pricing model would be simplistic, as it would not consider pricing as a key lever to maximize values. For example, in the case of a hotel (or an airline), the implicit value of an available room (or seat) depends not only on the average price charged for a night (or a flight) but also on the average occupancy rate. 
Coherently with the argument above, this work proposes a shift from the standard framework to a hedonic revenue model [1], where the dependent variable $(R)$ is a measure of unit revenue performance, standardized over the available inventory capacity. On one hand, the model includes a vector of variables $(P)$ concerning the pricing strategy, with particular reference to dynamic price variability. On the other hand, explanatory variables include the group of qualitative attributes $(H)$ that would be typically included in a hedonic pricing setting.

$$
R=\mathrm{f}(P, H)
$$

The inclusion of pricing variables as explanatory rather than dependent variables might raise causality concerns that need to be addressed in each empirical model specification.

In order to test this proposed empirical model, the next section presents a validation of the model in the hospitality industry.

\subsection{Data}

The empirical analysis consists of daily information on a sample of 840 hotels from 17 major European cities (Barcelona, Berlin, Brussels, Dublin, Edinburgh, Frankfurt, Geneva, Lisbon, London, Madrid, Milan, Moscow, Paris, Prague, Rome, Vienna and Zurich). Data was collected for four consecutive weeks in April 2016 (thus, 28 booking dates for each hotel). The final dataset originates from the matching of two sources of information: i) public information available on the web from an OTA and ii) access to a database offered by STR data center, an organization specialized in hotel data storage for academia and business.

Booking.com, the most popular distribution channel for hotels, was the selected OTA and provided the web-based information. As previously stressed, Booking.com operates through the agency model, which leaves inventory and price decisions to single hotels, leading to an environment with heterogeneous individual dynamic pricing strategies. Because the goal is to investigate the dynamic pricing strategies adopted by each hotel $(i)$, the same booking-date ( $t=1$ to 28 ) must be observed 
for a repeated number of times to check the price variability trajectory while approaching the checkin date. Data were collected by simulating the booking process using different days in advance $(d=$ $60,45,30,20,10,4,1$ and 0 days in advance). Consistently with this, while focusing on the month of April, the data collection process started at the beginning of February. To standardize the simulated booking process, the search concerned a single night reservation for one person. Each query provides information on the best available price for each 3,4 and 5 star hotel in the city centre, in accordance with some activated filtering options in the web search engine.

This data collection strategy records price changes while approaching the booking date and this strategy offers insights on intertemporal price distribution. In this respect, for each hotel and date and in order to capture the use of dynamic pricing strategies, we computed the median value of the price charged together with two measures: the intertemporal coefficient of price variation $(\mathrm{CV})$ and the price changes count (PCC). Figure 2 shows the distribution of $\mathrm{CV}$ in the sample. Most observations are in the range between 0.05 and 0.125 , while it is possible to see a small portion of hotel price observations without any intertemporal price variability (around 6.5\%). The median value is equal to 0.099 . This means that, if one considers a hotel room whose average price on booking.com is 100 Euro, the available price is likely to vary from 90 to 110 depending on the advance-booking horizon. $\mathrm{CV}$ exceeds 0.3 only in the $5 \%$ of observations. In these cases, with the same average price and advance-booking horizon as above, prices would likely be in the 70-130 range.

\section{[Insert Figure 2 here]}

Together with prices, the queries recorded data concerning some hedonic characteristics that are available in the search page for all the listings, i.e., the average online review score, the page position of the listing on the OTA and the hotel class. These hedonic attributes have been recognized by previous past hedonic literature in tourism. In particular, Yang et al. (2018) have shown, in a meta-analysis study, the role of online reviews on performance indicators and Abrate 
and Viglia (2016) have integrated reputational factors in tourism hedonic models. Additionally, Ert and Fleisher (2016) have disclosed the impact of mere position effects in booking hotels online and Melis and Piga (2017) have shown differential effects by putting hotel room class into the picture.

The database collected from the OTA was then matched with daily hotel performance data provided by STR Share Center. The database integrates information on the amount of rooms sold per day (daily occupancy rate) and the corresponding revenues, measured by the RevPar, i.e. the revenues per available room. This measure is commonly used in the hospitality industry as a key performance indicator, because it expresses the average unit revenue per available room and facilitates a direct comparison across hotels with different size (see Phillips et al., 2017). Different than a price level, this measure also accounts for inventory sold (i.e. the occupancy rate). The process of data matching was anonymized by STR and led to a final unbalanced panel database consisting of 21,687 valid observations.

\subsection{The empirical model}

The hedonic revenue model is estimated using a panel data specification. Equation 2 presents the baseline model.

$\ln \left(\operatorname{RevPar}_{i t}\right)=\alpha+\sum_{k} \beta_{k} P_{k i t}+\sum_{l} \beta_{l} H_{l i t}+\varepsilon_{i t}$

where: $P=\{$ median price; coefficient ofprice variation $\}$

$H=\{$ mean review rating; first page; hotel class dummies $\}$ 
In equation [2], $\alpha$ is a constant term, $\beta_{k}$, and $\beta_{l}$ are the vectors of coefficients associated with the different groups of independent variables for hotel $i$ in time $t$, and $\varepsilon_{i t}$ are the error terms (given the dimension of the dataset, $i=1, \ldots, 840$ cross-sectional units observed for dated periods $t=1, \ldots$, 28).

Specifically, the dependent variable is the RevPar (Revenue per available room), taken in its logarithmic form. We adopt a semi-logarithmic panel data regression to reduce the impact of extreme values. Consequently, the estimated coefficients are the percentage change in revenues caused by a unit-change in each independent variable.

In the baseline model, the vector describing the pricing strategy includes both a measure of price level, i.e. the median price level registered in the OTA, and a measure of price variability, i.e., the intertemporal coefficient of price variation, $C V$ (or, in an alternative specification, the price changes count, $P C C)$. The vector measuring hedonic variables $(H)$ includes the mean review rating, a dummy indicating whether the hotel was on the first page of the search results from the OTA (first page $^{1}$ and n-1 dummies regarding the STR hotel classification (luxury, upper upscale, upscale, upper midscale, midscale and economy class). In addition, the model includes city dummies to capture the geographical heterogeneity.

\footnotetext{
${ }^{1}$ An alternative specification considers the average page position.
} 
Table 1 shows summary statistics of the variables used in the analysis. The median price observation over the web was close to 250 Euros per night. The CV is on average equal to 0.126 , which means that prices tend to move downward or upward by almost 13 percent with respect to the mean price, depending on the time when a client makes the reservation for a certain hotel. The average review score measures the perceived quality of the hotels. Its average is around 8.5 out of a maximum of 10 . The revenue performance indicates that each available room pays off on average around 150 euros per night.

\section{[Insert Table 1 about here]}

The hedonic revenue model could raise endogeneity concerns due to the inclusion of pricing strategy as explanatory variables of unit revenues. In particular, the error term might be correlated with the alternative independent variables of interest proposed to pick up the level (the median) and the dynamics $(C V$ and $P C C)$ of prices on the OTA. This could happen if an unexpected event affects both performance and price changes at the same time. For instance, the propensity to modify prices can be greater when there is a higher than expected performance or when the dynamics of the pricing strategy might be driven by changes in macroeconomics variables that also have an impact on performance. Price variability would be having an influence on performance, but performance and especially its evolution over time - would be having an impact on the price variability. In particular, the error term $\varepsilon_{i t}$ can be seen as the sum of two terms: $u_{i t}$, which is not correlated with $P$, and $v_{i t}$, which is correlated with these price-related independent variables. The latter term $\left(v_{i t}\right)$ captures the effect of all latent variables that could have an impact on performance and the pricerelated variables.

To deal with and correct for this potential issue, we instrument $P$. When selecting the instruments, they must be correlated with these variables but not correlated with the latent variables included in 
$v_{i t}$ (Antonakis et al., 2012). Accordingly, we propose the specific daily observation regarding the three variables to be instrumented by their average values during the other 27 days of the month:

InstrMP $_{i t}=\frac{1}{27} \sum_{j \neq t}$ median price $i j ;$ InstrCV $_{i t}=\frac{1}{27} \sum_{j \neq t} C V_{i j} ; \quad \operatorname{InstrPCC} C_{i t}=\frac{1}{27} \sum_{j \neq t} P C C_{i j}$

The idea is that the pricing strategy in a specific booking date depends on contingent factors such as the specific daily performance, while the monthly average does not depend on specific daily circumstances. Thus, according to the instrumental variables procedure, all the independent variables are exogenous.

\section{Results and discussion}

[Insert Table 2 about here]

Table 2 presents the results of the effect of dynamic price variability on RevPar. The equations 1 through 4, which control for the city where the hotel is located ${ }^{2}$, show different specifications for the "coefficient of variation" and "price changes count's" instruments (InstrCV and InstrPCC, respectively). From these four equations, according to the goodness-of-fit measures, the optimum model is Model 1, with InstrCV as an instrument. The results show that the coefficient of variation presents a positive and significant effect on RevPar, which supports the idea that dynamic pricing strategies lead to higher revenue (in fact, the coefficient of variation, if included alone, explains more than $6 \%$ of the variability in revenues). To quantify this effect, if one simulates a change in the coefficient of price variation from the $1^{\text {st }}$ quartile to the $3^{\text {rd }}$ quartile, findings would reveal an impact of 3.07 percent. This means that, ceteris paribus, hotels making only moderate price adjustments over time are worse off when compared to hotels making more extensive dynamic price

\footnotetext{
${ }^{2}$ For the sake of space, the city-related parameters are not reported in Tables 1 and 2 but are available from the authors upon request.
} 
adjustments. $^{3}$ The model also controls for the variable "median price", which is positive and significant: the higher the prices the larger the RevPar. An alternative measure for the price levels in the OTA would have been the "average price". Since the coefficient of variation already includes the average price in its formula, the use of the median price was preferred. ${ }^{4}$

As to the hedonic variables of the model which is aimed at describing the qualitative level of the hotel, all STR classifications highlight a significant and positive coefficient. This indicates a higher RevPar than the reference alternative, which is Economy class. The same is true when considering the consumer-driven measure of quality represented by the mean review rating. More specifically, when all else is equal, each additional increase in the average review rating is associated with a 17.69 percent increase in RevPar. Moreover, the position on the web page shows that appearances on the first page bring greater RevPar by around 8 percent.

These results suggest that the benefits by charging different prices to the same tourism service (intertemporal price discrimination) and by limiting the number of units available before the demand is known (inventory control) outweigh the potential negative effects of any perceived price unfairness. Additionally, as clearly shown graphically in Figure 2, the widespread use of dynamic pricing in the observed sample (i.e., only $6.5 \%$ of cases not using any sort of intertemporal price variation) shows that there are no clear organizational issues in the adoption of dynamic pricing techniques in day-to-day hotel activities.

\footnotetext{
${ }^{3}$ As supplementary analysis, we separately measured the impact of positive and negative price changes. Only the impact of positive price changes was statistically significant.

${ }^{4}$ Results are robust to the inclusion of average price rather than median price. Also, we calculate different coefficients of variation and price changes count for different time windows (defined by distinct combinations obtained from the eight price points found on each of the booking dates analysed $(d=60,45,30,20,10,4,1$ and 0 days in advance)), and re-estimated the models. With a minimum of five observations per time window, we test another twelve different dynamic price-related variables: six for coefficient of variation and six for price changes count. The results obtained available on request- present robust results in the parameters of all the variables in the models in terms of sign and significance.
} 


\subsection{Robustness analysis}

This section extends the results obtained from Baseline Model 1 in three different ways: (i) by including additional control variables (Table 3a); (ii) by testing, as alternative dependent variables, the two constituents of RevPar, i.e., occupancy and average daily rate, $A D R$ (Table 3b); (iii) by employing a quantile regression specification to measure the effect of dynamic price variability on specific RevPar ranges (Table 3c).

\section{[Insert Table 3a about here]}

First, Table 3a presents different models that include additional relevant variables for dynamic price variability and its effect on RevPar. Model I shows the effect of room unavailability. Two variables are created: i) "unavailability" and ii) "strategic unavailability." The variable "unavailability" consists of those room rates that were closed before the end of the booking period and never opened again. The variable "strategic unavailability" shows room rates that were closed at some point before the end of the booking period but then re-opened before the check-in date at least once. Unavailability is not significant, so there is no effect on the RevPar. Closing the room rate and making it unavailable implies that these hotels are not making the most of price variability meaning they might be selling out at too low prices when they could have sold these rooms at a higher rate. Strategic unavailability is instead significant and positive, which means that selling out with a previous price dynamic strategy leads to higher RevPar (+8,6 percent). In other words, room rates that were re-opened at least once during the booking period lead to an increase in RevPar.

Model II analyzes the weekend effect. The days of the week are an essential component of revenue management with changing patterns of rates for weekdays and weekends. This model includes the effect of weekends and its interaction with the coefficient of price variation. While the main effect of weekdays is not significant, the interaction between weekends and price variation has a positive and significant parameter. Therefore, hotels implementing dynamic pricing strategy are better off 
than those that do not and this strategy pays off even more during the weekend $(p<0.05)$. This result could reflect a different consumer target, more leisure than business oriented, which might be more sensitive to price variations.

Model III and IV provide additional robustness checks, after including the effect of the interaction between the STR hotel classification and the mean review rating (Mariani and Borghi, 2018). The only significant interaction is "midscale class." The largest effect of review rating appears in lowprice properties. Finally, Model V estimates the central variables of interest by controlling for 476 interactions between cities and days of the month, so that potential demand shocks concerning the presence of particular events in a particular city in any day of the month are considered. The main variables of interest show the same signs and significance as the previous models.

[Insert Table 3b about here]

Models VI and VII in Table 3b unpack the impact of dynamic price variability on RevPar by considering its two constituents: the occupancy level and the ADR (since RevPar = Occupancy rate $\mathrm{x} A D R$ ). A higher extent of dynamic price variability significantly increases the occupancy rate, while it is associated with a lower average daily rate. Thus, on average, a higher dynamic price variability also implies discounting. However, the prevailing effect is the positive effect on occupancy, leading to an increase of revenues, coherently with the suggestions by Croes and Semrad (2012).

[Insert Table 3c about here]

Finally, the results of the quantile regression (Table 3c) indicate that the positive and significant impact of price variability is robust at all values of the RevPar distribution. Specifically, this impact tends to decrease while moving from lower to higher quantiles (from 0.40 at the $10^{\text {th }}$ quantile to 
0.20 at the $90^{\text {th }}$ quantile). Hence, dynamic price variability is particularly key for those hotels making relatively low revenues.

\section{Conclusions}

This study builds on the extensive theoretical literature in four domains, intertemporal price discrimination, price fairness, inventory controls and organizational culture. Since very few studies have managed to overcome the scarcity of appropriate data, this work measures whether or not and to what extent inter-temporal price variability benefits final revenues. The context of application is the hotel industry where, due to capacity constraints, revenue management strategies are key (Ye $e t$ al., 2018).

The paper makes at least three specific contributions. First, notwithstanding the presence of strategic customers and unfairness perceptions (Aviv and Pazgal, 2008; Tarrahi et al., 2016), dynamic price variability has a positive impact on revenue. In particular, with a sample of 21687 observations, we observe that a change in the coefficient of price variation between $1^{\text {st }}$ and $3^{\text {rd }}$ quartile brings about an average 3.07 percent increase in revenues. Second, the paper provides a methodological contribution in that it proposes a hedonic revenue model, also instrumenting dynamic price variability to solve endogeneity concerns. Specifically, all the models estimated show consistent signs and significance for the variable measuring "dynamic price variability". Third, hotel practitioners get a clear picture regarding the revenue maximization strategies with the biggest OTA operating with the agency model, i.e., Booking.com. Making correct price decisions is crucial to individual hotel performance in transaction based on the agency model. Our results suggest that hoteliers are not applying dynamic price variability enough and increasing the extent of the variability of prices would be helpful in terms of revenue maximization. Although it would be unrealistic to assume that increasing dynamic price variability indefinitely is a recipe for revenue 
success, in the set of data covering 17 cities and 21,687 observations, hotels are using dynamic price variability at a clear sub-optimal extent.

The empirical analysis controls for different levels of price rate, review ratings, page position in the OTA and days of the week, consistently with previous tourism hedonic literature showing the effect of these variables (Ert and Fleisher; 2016, Melis and Piga, 2017; Yang et al., 2018).

Interestingly, when rooms are made "strategically unavailable" for a period of time, this produces greater levels of revenue and reinforces the hypothesis that strategically implemented actions are linked to better performance. When compared to selling out as soon as possible, the application of dynamic pricing with a strategic insight attracts the highest valued customer.

This paper is not without limitations. Although nowadays around $70 \%$ reservations are made through OTAs (Lee, Guillet and Law, 2013), performance levels depend also on direct bookings. It would be relevant to see how hotel multi-channel approaches (see Yang and Leung, 2018) have an impact on revenues. Moreover, the data collection process was limited to single night reservations for a 4-week window horizon. As shown by Riasi, Schwartz Liu, and Li (2017), length-of-stay is an important variable for hotel revenue management, and the analysis of its interaction with dynamic price trajectory can represent a further direction of analysis. Price fairness has not been measured directly but instead elicited indirectly. While there is consistent evidence that higher price variability is strongly associated with higher perceived unfairness (Fosfuri, Giarratana, and Roca, 2015; Karande and Magnini, 2011), this study does not manipulate price unfairness directly.

Mass customization and personalized pricing have led the treatment of each individual as a market segment of size one. As a consequence, behavior-based price discrimination has created a framework where dynamic pricing is personalized to each customer (Richards et al., 2016). This generates an additional layer of analysis in this context, as price tailoring can moderate the effect of dynamic price variability on revenue. On this note, the customer's level of charged price for the core product can be determined by the consumption history of the supplementary services (rather 
than the core product itself). Hence, cross-product elasticity as a way to set prices for the core product could be an interesting avenue for future research. Another area for future research is the study of dynamic pricing in the context of cancellation policies, given that manipulating cancellation fees and deadline has a clear impact on revenues (Chen and Xie, 2013). Finally, hedonic elements may include additional hotel product differentiation variables (see Falk, 2008; Rigall-I-Torrent and Fluvià, 2011; Ropero 2011; Abrate, Fraquelli and Viglia, 2012) that were not retrievable. 


\section{References}

Abrate, G., Fraquelli, G., \& Viglia, G. (2012). Dynamic pricing strategies: Evidence from European hotels. International Journal of Hospitality Management, 31(1), 160-168.

Abrate, G., \& Viglia, G. (2016). Strategic and tactical price decisions in hotel revenue management. Tourism Management, 55, 123-132.

Alderighi, M., Nicolini, M., \& Piga, C. A. (2015). Combined effects of capacity and time on fares: insights from the yield management of a low-cost airline. Review of Economics and Statistics, 97(4), 900-915.

Alderighi, M., Nicolini, M., \& Piga, C. A. (2016). Targeting leisure and business passengers with unsegmented pricing. Tourism Management, 54, 502-512.

Anderson, C. K., \& Xie, X. (2010). Improving hospitality industry sales: Twenty-five years of revenue management. Cornell Hospitality Quarterly, 51(1), 53-67.

Anderson, C. K., \& Xie, X. (2016). Dynamic pricing in hospitality: overview and opportunities. International Journal of Revenue Management, 9(2-3), 165-174.

Armstrong, M. (2006). Recent developments in the economics of price discrimination. Cambridge University Press.

Antonakis, J., Bendahan, S., Jacquart, P., Lalive, R., \& Day, D. V. (2012). Causality and endogeneity: problems and solutions. The Oxford Handbook of Leadership and Organizations. Oxford University Press, Oxford.

Aubke, F., Woeber, K., Scott, N., \& Baggio, R. (2014). Knowledge sharing in revenue management teams: Antecedents and consequences of group cohesion. International Journal of Hospitality Management, 41, 149-157.

Aviv, Y., \& Pazgal, A. (2008). Optimal pricing of seasonal products in the presence of forwardlooking consumers. Manufacturing \& Service Operations Management, 10(3), 339-359.

Bayer, R. C. (2010). Intertemporal price discrimination and competition. Journal of economic behavior \& organization, 73(2), 273-293.

Bayoumi, A. E. M., Saleh, M., Atiya, A. F., \& Aziz, H. A. (2013). Dynamic pricing for hotel revenue management using price multipliers. Journal of Revenue and Pricing Management, 12(3), 271-285.

Bilotkach, V., Gaggero, A. A., \& Piga, C. A. (2015). Airline pricing under different market conditions: Evidence from European Low-Cost Carriers. Tourism Management, 47, 152-163.

Boyd, E. A., \& Bilegan, I. C. (2003). Revenue management and e-commerce. Management Science, 49(10), 1363-1386.

Mariani, M. M., \& Borghi, M. (2018). Effects of the Booking. com rating system: Bringing hotel class into the picture. Tourism Management, 66, 47-52.

Caillaud, B., \& De Nijs, R. (2014). Strategic loyalty reward in dynamic price discrimination. Marketing Science, 33(5), 725-742. 
Chen, Y., \& Cui, T. H. (2013). The benefit of uniform price for branded variants. Marketing Science, 32(1), 36-50.

Chen, C. C., \& Schwartz, Z. (2008). Timing matters: Travelers' advanced-booking expectations and decisions. Journal of Travel Research, 47(1), 35-42.

Chen, C. C., \& Xie, K. L. (2013). Differentiation of cancellation policies in the US hotel industry. International Journal of Hospitality Management, 34, 66-72.

Choi, S., \& Mattila, A. S. (2004). Hotel revenue management and its impact on customers' perceptions of fairness. Journal of Revenue and pricing Management, 2(4), 303-314.

Cohen-Vernik, D., \& Pazgal, A. (2017). Price Adjustment Policy with Partial Refunds. Journal of Retailing, 93(4), 507-526.

Combris, P., Lecocq, S., \& Visser, M. (1997). Estimation of a hedonic price equation for Bordeaux wine: does quality matter?. The Economic Journal, 107(441), 390-402.

Croes, R., \& Semrad, K. J. (2012). Does discounting work in the lodging industry?. Journal of Travel Research, 51(5), 617-631.

Dana, Jr, J. D. (1998). Advance-purchase discounts and price discrimination in competitive markets. Journal of Political Economy, 106(2), 395-422.

Dana Jr, J. D. (1999). Equilibrium price dispersion under demand uncertainty: the roles of costly capacity and market structure. The RAND Journal of Economics, 632-660.

Den Boer, A. V. (2015). Dynamic pricing and learning: historical origins, current research, and new directions. Surveys in operations research and management science, 20(1), 1-18.

Deneckere, R., \& Peck, J. (2012). Dynamic competition with random demand and costless search: A theory of price posting. Econometrica, 80(3), 1185-1247.

Dutta, S., Zbaracki, M. J., \& Bergen, M. (2003). Pricing process as a capability: A resource- based perspective. Strategic management journal, 24(7), 615-630.

Elmaghraby, W., \& Keskinocak, P. (2003). Dynamic pricing in the presence of inventory considerations: Research overview, current practices, and future directions. Management science, 49(10), 1287-1309.

Enz, C. A., Canina, L., \& Lomanno, M. V. (2004). Why discounting doesn't work. The Center for Hospitality Research Reports, 4(7), 1-28.

Enz, C. A., Canina, L., \& Rest, J. P. I. V. D. (2016). Hotel strategic pricing in Europe: a 10-year exploration of competition. International Journal of Revenue Management, 9(2-3), 92-107.

Ert, E., \& Fleischer, A. (2016). Mere position effect in booking hotels online. Journal of Travel Research, 55(3), 311-321.

Falk, M. (2008). A hedonic price model for ski lift tickets. Tourism Management, 29(6), 1172-1184.

Fosfuri, A., Giarratana, M. S., \& Roca, E. (2015). Walking a slippery line: Investments in social values and product longevity. Strategic management journal, 36(11), 1750-1760. 
Gaggero, A. A., \& Piga, C. A. (2011). Airline market power and intertemporal price dispersion. The Journal of Industrial Economics, 59(4), 552-577.

Gallego, D. G., \& Van Ryzin, G. (1994). Optimal dynamic pricing of inventories with stochastic demand over finite horizons. Management science, 40(8), 999-1020.

Grewal, D., Ailawadi, K. L., Gauri, D., Hall, K., Kopalle, P., \& Robertson, J. R. (2011). Innovations in retail pricing and promotions. Journal of Retailing, 87, S43-S52.

Guillet, B., \& Mohammed, I. (2015). Revenue management research in hospitality and tourism: A critical review of current literature and suggestions for future research. International Journal of Contemporary Hospitality Management, 27(4), 526-560.

Harding, J. P., Rosenthal, S. S., \& Sirmans, C. F. (2003). Estimating bargaining power in the market for existing homes. Review of Economics and statistics, 85(1), 178-188.

Haws, K. L., \& Bearden, W. O. (2006). Dynamic pricing and consumer fairness perceptions. Journal of Consumer Research, 33(3), 304-311.

Hayes, K. J., \& Ross, L. B. (1998). Is airline price dispersion the result of careful planning or competitive forces?. Review of Industrial Organization, 13(5), 523-541.

Heo, C. Y., \& Lee, S. (2011). Influences of consumer characteristics on fairness perceptions of revenue management pricing in the hotel industry. International Journal of Hospitality Management, 30(2), 243-251.

Hua, N., \& Yang, Y. (2017). Systematic effects of crime on hotel operating performance. Tourism Management, 60, 257-269.

Huppertz, J. W., Arenson, S. J., \& Evans, R. H. (1978). An application of equity theory to buyerseller exchange situations. Journal of marketing research, 250-260.

Kalnins, A. (2016). Beyond Manhattan: Localized competition and organizational failure in urban hotel markets throughout the United States, 2000-2014. Strategic Management Journal, 37(11), 2235-2253.

Karande, K., \& Magnini, V. P. (2011). The relative use of contextual and temporal reference price components in hotel and airline purchases. Journal of Hospitality \& Tourism Research, 35(1), 119141.

Kimes, S. E. (1994). Perceived Fairness of Yield Management: Applying yield-management principles to rate structures is complicated by what consumers perceive as unfair practices. Cornell Hotel and Restaurant Administration Quarterly, 35(1), 22-29.

Lancaster, K. J. (1966). A new approach to consumer theory. Journal of political economy, 74(2), 132-157.

Lee, H. A., Denizci Guillet, B., \& Law, R. (2013). An examination of the relationship between online travel agents and hotels: A case study of Choice Hotels International and Expedia. com. Cornell Hospitality Quarterly, 54(1), 95-107.

Lott, J. R., \& Roberts, R. D. (1991). A guide to the pitfalls of identifying price discrimination. Economic Inquiry, 29(1), 14-23. 
Malasevska, I., \& Haugom, E. (2018). Optimal prices for alpine ski passes. Tourism Management, 64, 291-302.

McAfee, R. P., \& Te Velde, V. (2006). Dynamic pricing in the airline industry.forthcoming in Handbook on Economics and Information Systems, Ed: TJ Hendershott, Elsevier.

Melis, G., \& Piga, C. A. (2017). Are all online hotel prices created dynamic? An empirical assessment. International Journal of Hospitality Management, 67, 163-173.

Noone, B. M., Canina, L., \& Enz, C. A. (2013). Strategic price positioning for revenue management: The effects of relative price position and fluctuation on performance. Journal of Revenue and Pricing Management, 12(3), 207-220.

Oskam, J., van der Rest, J. P., \& Telkamp, B. (2018). What's mine is yours-but at what price? Dynamic pricing behavior as an indicator of Airbnb host professionalization. Journal of Revenue and Pricing Management, 17(5), 311-328.

Phillips, P., Barnes, S., Zigan, K., \& Schegg, R. (2017). Understanding the impact of online reviews on hotel performance: an empirical analysis. Journal of Travel Research, 56(2), 235-249.

Riasi, A., Schwartz, Z., Liu, X., \& Li, S. (2017). Revenue management and length-of-stay-based room pricing. Cornell Hospitality Quarterly, 58(4), 393-399.

Richards, T. J., Gómez, M. I., \& Pofahl, G. (2012). A multiple-discrete/continuous model of price promotion. Journal of Retailing, 88(2), 206-225.

Richards, T. J., Liaukonyte, J., \& Streletskaya, N. A. (2016). Personalized pricing and price fairness. International Journal of Industrial Organization, 44, 138-153.

Rigall-I-Torrent, R., \& Fluvià, M. (2011). Managing tourism products and destinations embedding public good components: A hedonic approach. Tourism Management, 32(2), 244-255.

Ropero, M. A. (2011). Dynamic pricing policies of hotel establishments in an online travel agency. Tourism economics, 17(5), 1087-1102.

Sahut, J. M., Hikkerova, L., \& Pupion, P. C. (2016). Perceived unfairness of prices resulting from yield management practices in hotels. Journal of Business Research, 69(11), 4901-4906.

Selmi, N., \& Dornier, R. (2011). Yield management in the French hotel business: An assessment of the importance of the human factor. International Business Research, 4(2), 58.

Şen, A. (2013). A comparison of fixed and dynamic pricing policies in revenue management. Omega, 41(3), 586-597.

Stavins, J. (2001). Effect of consumer characteristics on the use of payment instruments. New England Economic Review, (3), 19.

Stokey, N. L. (1979). Intertemporal price discrimination. The Quarterly Journal of Economics, 355371.

$\mathrm{Su}, \mathrm{X}$. (2007). Intertemporal pricing with strategic customer behavior. Management Science, 53(5), 726-741. 
Sweeting, A. (2012). Dynamic pricing behavior in perishable goods markets: Evidence from secondary markets for major league baseball tickets. Journal of Political Economy, 120(6), 11331172.

Talluri, K. T., \& Van Ryzin, G. J. (2004). The Theory and Practice of Revenue Management Springer. New York.

Tarrahi, F., Eisend, M., \& Dost, F. (2016). A meta-analysis of price change fairness perceptions. International Journal of Research in Marketing, 33(1), 199-203.

Thaler, R. H. (2008). Mental accounting and consumer choice. Marketing Science, 27(1), 15-25.

Van der Rest, J. P. I., \& Harris, P. J. (2008). Optimal imperfect pricing decision-making: Modifying and applying Nash's rule in a service sector context. International Journal of Hospitality Management, 27(2), 170-178.

Van der Rest, J. P., Roper, A., \& Wang, X. L. (2018). Why is a change of company pricing policy so hard to implement?. International Journal of Hospitality Management, 69, 30-40.

Verhoef, P. C., Kannan, P. K., \& Inman, J. J. (2015). From multi-channel retailing to omni-channel retailing: introduction to the special issue on multi-channel retailing. Journal of retailing, 91(2), 174-181.

Viglia, G., \& Abrate, G. (2014). How social comparison influences reference price formation in a service context. Journal of Economic Psychology, 45, 168-180.

Viglia, G., Mauri, A., \& Carricano, M. (2016). The exploration of hotel reference prices under dynamic pricing scenarios and different forms of competition. International Journal of Hospitality Management, 52, 46-55.

Villas-Boas, J. M. (1999). Dynamic competition with customer recognition. The Rand Journal of Economics, 604-631.

Weatherford, L. R., \& Bodily, S. E. (1992). A taxonomy and research overview of perishable-asset revenue management: Yield management, overbooking, and pricing. Operations research, 40(5), 831-844.

Xia, L., Monroe, K. B., \& Cox, J. L. (2004). The price is unfair! A conceptual framework of price fairness perceptions. Journal of marketing, 68(4), 1-15.

Xie, K. L., \& Kwok, L. (2017). The effects of Airbnb's price positioning on hotel performance. International Journal of Hospitality Management, 67, 174-184.

Yang, Y., \& Leung, X. Y. (2018). A better last-minute hotel deal via app? Cross-channel price disparities between HotelTonight and OTAs. Tourism Management, 68, 198-209.

Yang, Y., Park, S., \& Hu, X. (2018). Electronic word of mouth and hotel performance: A metaanalysis. Tourism Management, 67, 248-260.

Ye, F., Zhang, L., \& Li, Y. (2017). Strategic choice of sales channel and business model for the hotel supply chain. Journal of Retailing, 94(1), 33-44. 
Figure 1. Constituents of the impact of dynamic price variability on revenue maximization (assuming equal hedonic characteristics)

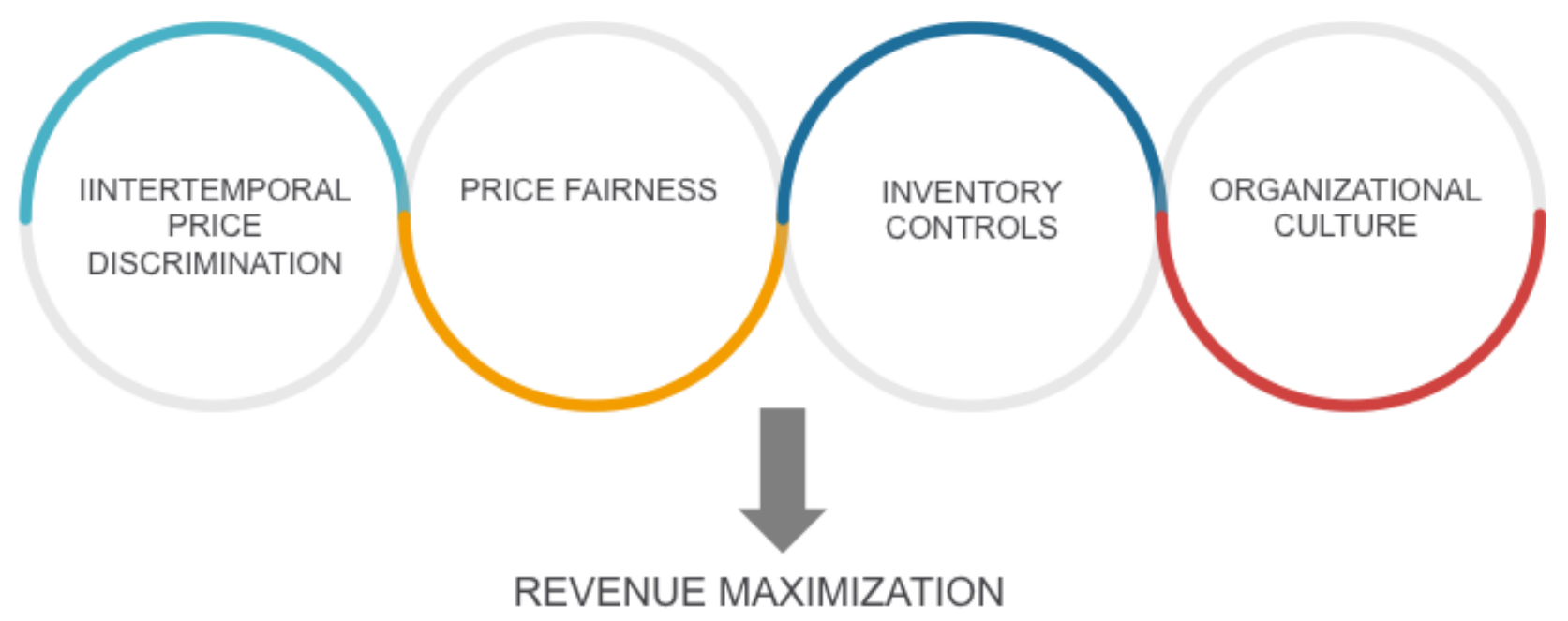


Figure 2. Distribution of the value of dynamic price variability

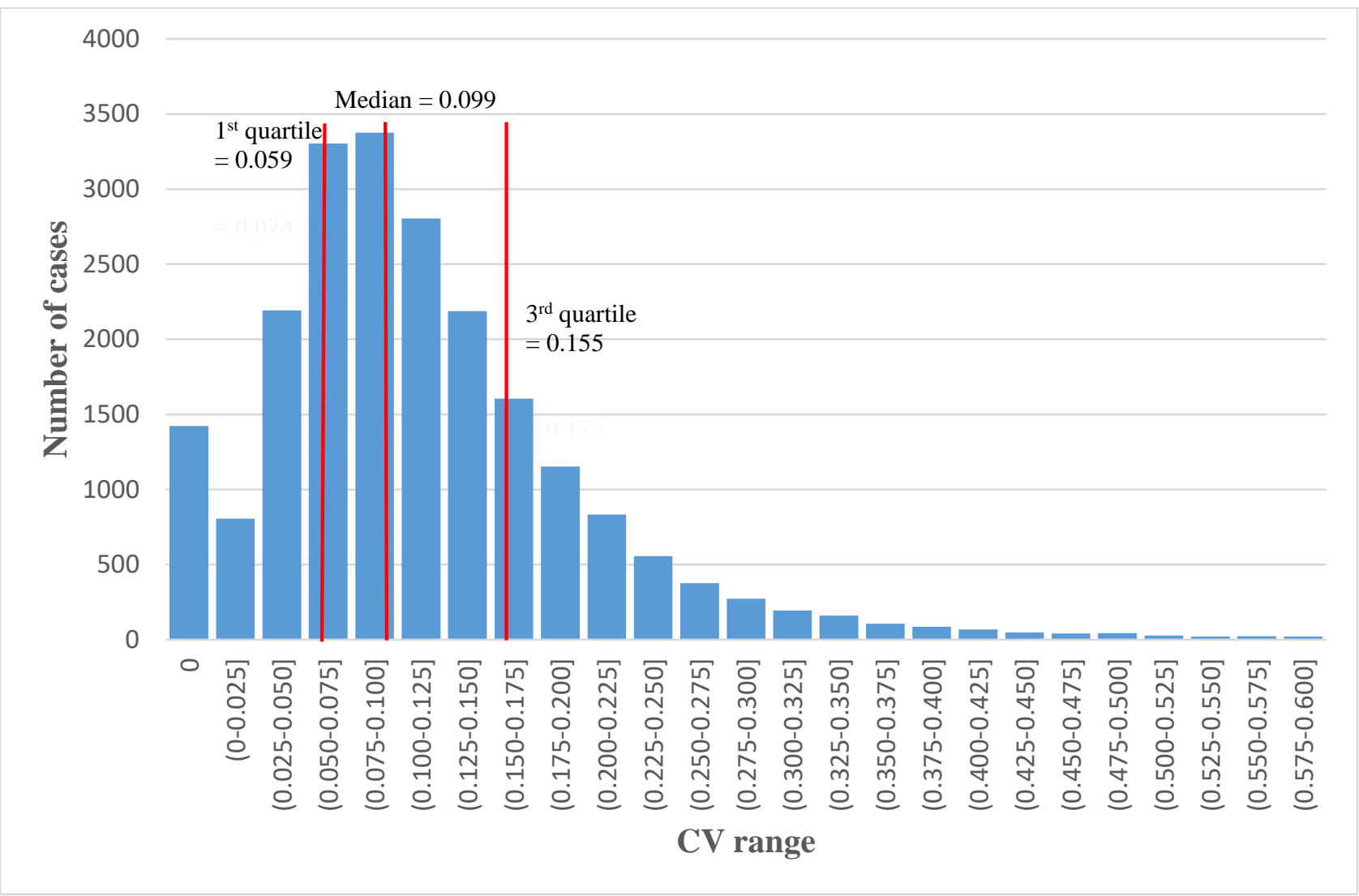


Table 1. Summary statistics

\begin{tabular}{|c|c|c|c|c|c|}
\hline Group of Variables & Variable & Mean & Standard deviation & Min & Max \\
\hline \multirow{3}{*}{ Price variables $(P)$} & Coefficient of price variation & 0.120 & 0.108 & 0 & 1.551 \\
\hline & Price changes count & 4.503 & 2.111 & 0 & 7 \\
\hline & Median Price & 244.9 & 184.1 & 40 & 6490 \\
\hline \multirow{8}{*}{ Hedonic variables $(H)$} & Mean review rating & 8.502 & 0.518 & 6.6 & 9.8 \\
\hline & First page & 0.176 & 0.380 & 0 & 1 \\
\hline & Average page position & 6.422 & 6.522 & 1 & 53 \\
\hline & Luxury class & 0.228 & 0.419 & 0 & 1 \\
\hline & Upper upscale & 0.268 & 0.443 & 0 & 1 \\
\hline & Upscale class & 0.312 & 0.463 & 0 & 1 \\
\hline & Upper midscale class & 0.117 & 0.321 & 0 & 1 \\
\hline & Midscale class & 0.033 & 0.178 & 0 & 1 \\
\hline Unit revenues $(R)$ & RevPar & 148.8 & 114.4 & 7.630 & 1629.74 \\
\hline
\end{tabular}


Table 2. Effect of dynamic price variability on RevPar (Baseline models)

(Standard errors in parenthesis)

\begin{tabular}{|c|c|c|c|c|}
\hline Variables & $\begin{array}{c}\text { Baseline model } \\
1\end{array}$ & $\begin{array}{c}\text { Baseline model } \\
2\end{array}$ & $\begin{array}{c}\text { Baseline model } \\
3\end{array}$ & $\begin{array}{c}\text { Baseline model } \\
4\end{array}$ \\
\hline $\begin{array}{l}\text { Coefficient of price } \\
\text { variation (InstrCV) }\end{array}$ & $\begin{array}{c}0.3243^{\mathrm{a}} \\
(0.0567)\end{array}$ & & $\begin{array}{c}0.2906^{\mathrm{a}} \\
(0.0726)\end{array}$ & \\
\hline $\begin{array}{l}\text { Price changes count } \\
\text { (InstrPCC) }\end{array}$ & & $\begin{array}{l}0.0160^{\mathrm{a}} \\
(0.0032)\end{array}$ & & $\begin{array}{l}0.0106^{\mathrm{a}} \\
(0.0035)\end{array}$ \\
\hline Median Price (InstrMP) & $\begin{array}{c}0.0017^{\mathrm{a}} \\
(0.00002)\end{array}$ & $\begin{array}{c}0.0017^{\mathrm{a}} \\
(0.00002)\end{array}$ & $\begin{array}{c}0.0013 \\
(0.0013)\end{array}$ & $\begin{array}{c}0.0017^{\mathrm{a}} \\
(0.00002)\end{array}$ \\
\hline Mean review rating & $\begin{array}{l}0.1769^{\mathrm{a}} \\
(0.0060)\end{array}$ & $\begin{array}{c}0.175^{\mathrm{a}} \\
(0.0060)\end{array}$ & $\begin{array}{l}0.2144^{\mathrm{c}} \\
(0.0883)\end{array}$ & $\begin{array}{l}0.1790^{\mathrm{a}} \\
(0.0060)\end{array}$ \\
\hline First page & $\begin{array}{l}0.0774^{\mathrm{a}} \\
(0.0068)\end{array}$ & $\begin{array}{l}0.0716^{\mathrm{a}} \\
(0.0069)\end{array}$ & & \\
\hline Average page position & & & $\begin{array}{l}-0.0004^{\mathrm{a}} \\
(0.0001)\end{array}$ & $\begin{array}{l}-0.0004^{\mathrm{a}} \\
(0.00003)\end{array}$ \\
\hline Luxury class & $\begin{array}{l}0.3919^{\mathrm{a}} \\
(0.0196)\end{array}$ & $\begin{array}{l}0.3814^{\mathrm{a}} \\
(0.0201)\end{array}$ & $\begin{array}{c}0.4752 \\
(0.2743)\end{array}$ & $\begin{array}{l}0.3739^{\mathrm{a}} \\
(0.0201)\end{array}$ \\
\hline Upper upscale & $\begin{array}{l}0.3381^{\mathrm{a}} \\
(0.0181)\end{array}$ & $\begin{array}{r}0.3308^{a} \\
(0.0185)\end{array}$ & $\begin{array}{l}0.3567^{a} \\
(0.0810)\end{array}$ & $\begin{array}{r}0.3292^{\mathrm{a}} \\
(0.0185)\end{array}$ \\
\hline Upscale class & $\begin{array}{r}0.2225^{\mathrm{a}} \\
(0.0175)\end{array}$ & $\begin{array}{l}0.2113^{\mathrm{a}} \\
(0.0180)\end{array}$ & $\begin{array}{l}0.2175^{\mathrm{a}} \\
(0.0316)\end{array}$ & $\begin{array}{r}0.2055^{\mathrm{a}} \\
(0.0180)\end{array}$ \\
\hline Upper midscale class & $\begin{array}{l}0.1219^{a} \\
(0.0184)\end{array}$ & $\begin{array}{l}0.1173^{\mathrm{a}} \\
(0.0186)\end{array}$ & $\begin{array}{l}0.1225^{\mathrm{a}} \\
(0.0282)\end{array}$ & $\begin{array}{l}0.1164^{\mathrm{a}} \\
(0.0186)\end{array}$ \\
\hline Midscale class & $\begin{array}{c}0.0955^{\mathrm{a}} \\
(0.0210)\end{array}$ & $\begin{array}{c}0.0849^{a} \\
(0.0213)\end{array}$ & $\begin{array}{c}0.0901^{\mathrm{a}} \\
(0.0214)\end{array}$ & $\begin{array}{c}0.0841^{\mathrm{a}} \\
(0.0213)\end{array}$ \\
\hline Cities & Yes & Yes & Yes & Yes \\
\hline Constant & $\begin{array}{c}2.3482^{\mathrm{a}} \\
(0.0531)\end{array}$ & $\begin{array}{c}2.3489^{a} \\
(0.0536)\end{array}$ & $\begin{array}{c}2.1217^{\mathrm{a}} \\
(0.6195)\end{array}$ & $\begin{array}{c}2.3681^{\mathrm{a}} \\
(0.0539)\end{array}$ \\
\hline R-squared & 0.6763 & 0.6753 & 0.6761 & 0.6750 \\
\hline Adjusted R-squared & 0.6759 & 0.6750 & 0.6758 & 0.6746 \\
\hline F-statistic & $1445.92^{\mathrm{a}}$ & $1446.18^{\mathrm{a}}$ & $1155.16^{\mathrm{a}}$ & $1445.48^{\mathrm{a}}$ \\
\hline
\end{tabular}

$a=p<0.001 ; b=p<0.01 ; c=p<0.05$ 
Table 3a. Effect of dynamic price variability on RevPar (additional explanatory variables) (Standard errors in parenthesis)

\begin{tabular}{|c|c|c|c|c|c|}
\hline Variables & Model I & Model II & Model III & Model IV & Model V \\
\hline Coefficient of price variation (InstrCV) & $\begin{array}{c}0.4192^{\mathrm{a}} \\
(0.0563)\end{array}$ & $\begin{array}{c}0.2212^{\mathrm{a}} \\
(0.0674)\end{array}$ & $\begin{array}{c}0.3411^{\mathrm{a}} \\
(0.0572)\end{array}$ & $\begin{array}{c}0.3341^{\mathrm{a}} \\
(0.0673)\end{array}$ & $\begin{array}{c}0.3308^{\mathrm{a}} \\
(0.0481)\end{array}$ \\
\hline Median Price (InstrPr) & $\begin{array}{c}0.0017^{\mathrm{a}} \\
(0.0000)\end{array}$ & $\begin{array}{c}0.0017^{\mathrm{a}} \\
(0.0000)\end{array}$ & $\begin{array}{c}0.0018^{\mathrm{a}} \\
(0.0000)\end{array}$ & $\begin{array}{c}0.0017^{\mathrm{a}} \\
(0.0000)\end{array}$ & $\begin{array}{c}0.0017^{\mathrm{a}} \\
(0.0000)\end{array}$ \\
\hline Mean review rating & $\begin{array}{l}0.1749^{a} \\
(0.0059)\end{array}$ & $\begin{array}{c}0.1768^{a} \\
(0.0060)\end{array}$ & $\begin{array}{c}0.1887^{\mathrm{a}} \\
(0.0300)\end{array}$ & $\begin{array}{l}0.1822^{a} \\
(0.0299)\end{array}$ & $\begin{array}{c}0.1793^{\mathrm{a}} \\
(0.0051)\end{array}$ \\
\hline First page & $\begin{array}{c}0.0899^{a} \\
(0.0068)\end{array}$ & $\begin{array}{c}0.0778^{a} \\
(0.0068)\end{array}$ & $\begin{array}{c}0.0762^{\mathrm{a}} \\
(0.0068)\end{array}$ & $\begin{array}{c}0.0893^{\mathrm{a}} \\
(0.0069)\end{array}$ & $\begin{array}{c}0.0805^{\mathrm{a}} \\
(0.0059)\end{array}$ \\
\hline Weekend & & $\begin{array}{c}-0.0269 \\
(0.0146)\end{array}$ & & $\begin{array}{c}-0.0240 \\
(0.0145)\end{array}$ & \\
\hline Weekend*InstrCV & & $\begin{array}{c}0.3405^{\mathrm{a}} \\
(0.1116)\end{array}$ & & $\begin{array}{c}0.3348^{b} \\
(0.1108)\end{array}$ & \\
\hline Unavailability & $\begin{array}{c}0.0068 \\
(0.0078)\end{array}$ & & & $\begin{array}{c}0.0075 \\
(0.0078)\end{array}$ & \\
\hline Strategic unavailability & $\begin{array}{l}0.0864^{\mathrm{a}} \\
(0.0055)\end{array}$ & & & $\begin{array}{c}0.0860^{\mathrm{a}} \\
(0.0055)\end{array}$ & \\
\hline Luxury class & $\begin{array}{c}0.4106^{\mathrm{a}} \\
(0.0195)\end{array}$ & $\begin{array}{c}0.3921^{\mathrm{a}} \\
(0.0196)\end{array}$ & $\begin{array}{c}0.7233^{\mathrm{b}} \\
(0.2708)\end{array}$ & $\begin{array}{c}0.6727^{c} \\
(0.2698)\end{array}$ & $\begin{array}{c}0.3499^{\mathrm{a}} \\
(0.0166)\end{array}$ \\
\hline Upper upscale & $\begin{array}{c}0.3515^{\mathrm{a}} \\
(0.0180)\end{array}$ & $\begin{array}{c}0.3385^{\mathrm{a}} \\
(0.0181)\end{array}$ & $\begin{array}{l}0.8044^{\mathrm{b}} \\
(0.2565)\end{array}$ & $\begin{array}{c}0.7700^{\mathrm{b}} \\
(0.2556)\end{array}$ & $\begin{array}{c}0.2992^{\mathrm{a}} \\
(0.0154)\end{array}$ \\
\hline Upscale class & $\begin{array}{c}0.2362^{\mathrm{a}} \\
(0.0174)\end{array}$ & $\begin{array}{c}0.2224^{\mathrm{a}} \\
(0.0176)\end{array}$ & $\begin{array}{c}0.0252 \\
(0.2593)\end{array}$ & $\begin{array}{c}0.0196 \\
(0.2584)\end{array}$ & $\begin{array}{c}0.1850^{\mathrm{a}} \\
(0.0149)\end{array}$ \\
\hline Upper midscale class & $\begin{array}{c}0.1297^{a} \\
(0.0183)\end{array}$ & $\begin{array}{c}0.1218^{a} \\
(0.0184)\end{array}$ & $\begin{array}{c}-0.0452 \\
(0.2729)\end{array}$ & $\begin{array}{c}-0.0771 \\
(0.2720)\end{array}$ & $\begin{array}{c}0.0854^{\mathrm{a}} \\
(0.0157)\end{array}$ \\
\hline Midscale class & $\begin{array}{c}0.1072^{\mathrm{a}} \\
(0.0209)\end{array}$ & $\begin{array}{c}0.0950^{\mathrm{a}} \\
(0.0211)\end{array}$ & $\begin{array}{l}-0.7666^{c} \\
(0.3194)\end{array}$ & $\begin{array}{l}-0.7322^{c} \\
(0.3183)\end{array}$ & $\begin{array}{c}0.0595^{\mathrm{a}} \\
(0.0179)\end{array}$ \\
\hline Luxury class*Mean review rating & & & $\begin{array}{l}-0.0392 \\
(0.0330)\end{array}$ & $\begin{array}{l}-0.0309 \\
(0.0329)\end{array}$ & \\
\hline Upper upscale*Mean review rating & & & $\begin{array}{c}-0.0560 \\
(0.0316)\end{array}$ & $\begin{array}{c}-0.0501 \\
(0.0315)\end{array}$ & \\
\hline Upscale class* Mean review rating & & & $\begin{array}{c}0.0225 \\
(0.0320)\end{array}$ & $\begin{array}{c}0.0250 \\
(0.0319)\end{array}$ & \\
\hline $\begin{array}{l}\text { Upper midscale class*Mean review } \\
\text { rating }\end{array}$ & & & $\begin{array}{c}0.0201 \\
(0.0338)\end{array}$ & $\begin{array}{c}0.0251 \\
(0.0337)\end{array}$ & \\
\hline Midscale class* Mean review rating & & & $\begin{array}{l}0.1061^{\mathrm{a}} \\
(0.0395)\end{array}$ & $\begin{array}{l}0.1033^{b} \\
(0.0394)\end{array}$ & \\
\hline Cities & Yes & Yes & Yes & Yes & \\
\hline Cities*day & & & & & Yes \\
\hline Constant & $\begin{array}{c}2.2980^{\mathrm{a}} \\
(0.0529) \\
\end{array}$ & $\begin{array}{c}2.3578^{a} \\
(0.0534)\end{array}$ & $\begin{array}{c}2.2607^{\mathrm{a}} \\
(0.2432)\end{array}$ & $\begin{array}{c}2.2556^{\mathrm{a}} \\
(0.2424)\end{array}$ & $\begin{array}{c}2.3630^{\mathrm{a}} \\
(0.0452) \\
\end{array}$ \\
\hline R-squared & 0.6806 & 0.6748 & 0.6765 & 0.6795 & 0.7704 \\
\hline Adjusted R-squared & 0.6802 & 0.6744 & 0.6761 & 0.6790 & 0.7655 \\
\hline F-statistic & $1398.09^{\mathrm{a}}$ & $1343.18^{\mathrm{a}}$ & $1208.75^{\mathrm{a}}$ & $1117.47^{\mathrm{a}}$ & $185.41^{\mathrm{a}}$ \\
\hline
\end{tabular}


Table 3b. Effect of dynamic price variability on occupancy and $A D R$ (Standard errors in parenthesis)

\begin{tabular}{lcc}
\hline \hline Variables & $\begin{array}{c}\text { Model VI } \\
\text { DV=Occupancy }\end{array}$ & $\begin{array}{c}\text { Model VII } \\
\text { DV=In(ADR) }\end{array}$ \\
\hline Coefficient of price variation (InstrCV) & $0.4003^{\mathrm{a}}$ & $-0.2711^{\mathrm{a}}$ \\
Median Price (InstrPr) & $(0.0275)$ & $(0.0399)$ \\
Mean review rating & $-0.0003^{\mathrm{a}}$ & $0.0021^{\mathrm{a}}$ \\
& $(0.0001)$ & $(0.0001)$ \\
First page & $0.0229^{\mathrm{a}}$ & $0.141^{\mathrm{a}}$ \\
& $(0.0029)$ & $(0.0042)$ \\
Luxury class & -0.0020 & $0.0799^{\mathrm{a}}$ \\
& $(0.0033)$ & $(0.0048)$ \\
Upper upscale & $-0.0829^{\mathrm{a}}$ & $0.5187^{\mathrm{a}}$ \\
& $(0.0095)$ & $(0.0138)$ \\
Upscale class & $-0.0257 \mathrm{~b}$ & $0.3808^{\mathrm{a}}$ \\
& $(0.0088)$ & $(0.0127)$ \\
Upper midscale class & -0.0056 & $0.2353^{\mathrm{a}}$ \\
Midscale class & $(0.0085)$ & $(0.0123)$ \\
Cities & -0.0046 & $0.1378^{\mathrm{a}}$ \\
Constant & $(0.0089)$ & $(0.0129)$ \\
& $0.0289 \mathrm{~b}$ & $0.058^{\mathrm{a}}$ \\
F-statistic & $(0.0102)$ & $(0.0148)$ \\
\hline \hline
\end{tabular}

$a=p<0.001 ; b=p<0.01 ; c=p<0.05$ 
Table 3c. Effect of dynamic price variability on RevPar (Quantile regression) (Standard errors in parenthesis)

\begin{tabular}{|c|c|c|c|c|c|}
\hline \multirow{2}{*}{ Variables } & \multicolumn{5}{|c|}{ Quantiles } \\
\hline & 0.1 & 0.25 & 0.5 & 0.75 & 0.9 \\
\hline \multirow[t]{2}{*}{ Coefficient of price variation (InstrCV) } & $0.4023^{\mathrm{a}}$ & $0.3746^{\mathrm{a}}$ & $0.2807^{\mathrm{a} *}$ & $0.1813^{\mathrm{a} *}$ & $0.1991^{\mathrm{a}}$ \\
\hline & $(0.0356)$ & $(0.0269)$ & $(0.0208)$ & $(0.0232)$ & $(0.0246)$ \\
\hline \multirow[t]{2}{*}{ Median Price (InstrPr) } & $0.0015^{\mathrm{a}}$ & $0.0020^{\mathrm{a} *}$ & $0.0023^{\mathrm{a} *}$ & $0.0026^{\mathrm{a} *}$ & $0.0028^{a *}$ \\
\hline & $(0.0001)$ & $(0.000)$ & $(0.000)$ & $(0.0001)$ & $(0.0001)$ \\
\hline \multirow[t]{2}{*}{ Mean review rating } & $0.2289^{a *}$ & $0.1828^{a *}$ & $0.1389^{a *}$ & $0.1010^{\mathrm{a} *}$ & $0.0859^{\mathrm{a} *}$ \\
\hline & $(0.0134)$ & $(0.0076)$ & $(0.0063)$ & $(0.0059)$ & $(0.0065)$ \\
\hline \multirow[t]{2}{*}{ First page } & $0.0909^{\mathrm{a}}$ & $0.0865^{\mathrm{a}}$ & $0.0826^{\mathrm{a}}$ & $0.0806^{\mathrm{a}}$ & $0.0553^{\mathrm{a} *}$ \\
\hline & $(0.0146)$ & $(0.0093)$ & $(0.0068)$ & $(0.0057)$ & $(0.0056)$ \\
\hline \multirow[t]{2}{*}{ Luxury class } & $0.3769^{a}$ & $0.3776^{\mathrm{a}}$ & $0.3471^{\mathrm{a}}$ & $0.2612^{\mathrm{a} *}$ & $0.1757^{\mathrm{a} *}$ \\
\hline & $(0.0373)$ & $(0.024)$ & $(0.0221)$ & $(0.0282)$ & $(0.0221)$ \\
\hline \multirow[t]{2}{*}{ Upper upscale } & $0.3425^{\mathrm{a}}$ & $0.3851^{\mathrm{a}}$ & $0.3671^{\mathrm{a}}$ & $0.2765^{\mathrm{a} *}$ & $0.1627^{a *}$ \\
\hline & $(0.0346)$ & $(0.0201)$ & $(0.0200)$ & $(0.0270)$ & $(0.0203)$ \\
\hline \multirow[t]{2}{*}{ Upscale class } & $0.1975^{\mathrm{a}}$ & $0.2735^{\mathrm{a} *}$ & $0.2771^{\mathrm{a}}$ & $0.1877^{\mathrm{a} *}$ & $0.0728^{\mathrm{a} *}$ \\
\hline & $(0.0333)$ & $(0.0199)$ & $(0.0197)$ & $(0.0265)$ & $(0.0205)$ \\
\hline \multirow[t]{2}{*}{ Upper midscale class } & $0.1176^{\mathrm{b}}$ & $0.1964^{\mathrm{a} *}$ & $0.1842^{\mathrm{a}}$ & $0.0901^{\mathrm{a} *}$ & $-0.0135^{*}$ \\
\hline & $(0.0368)$ & $(0.0209)$ & $(0.0198)$ & $(0.027)$ & $(0.0208)$ \\
\hline \multirow[t]{2}{*}{ Midscale class } & $0.0957^{\mathrm{c}}$ & $0.1121^{\mathrm{a}}$ & $0.1239^{a}$ & $0.0823 b$ & $0.0092 *$ \\
\hline & $(0.0396)$ & $(0.024)$ & $(0.0222)$ & $(0.0297)$ & $(0.0239)$ \\
\hline Cities & Yes & Yes & Yes & Yes & Yes \\
\hline \multirow{2}{*}{ Constant } & $1.5619^{\mathrm{a}}$ & $2.0634^{\mathrm{a}}$ & $2.5987^{\mathrm{a}}$ & $3.1251^{\mathrm{a}}$ & $3.4658^{\mathrm{a}}$ \\
\hline & $(0.1142)$ & $(0.0656)$ & $(0.0551)$ & $(0.0588)$ & $(0.054)$ \\
\hline Pseudo R-squared & 0.3758 & 0.4189 & 0.4826 & 0.5435 & 0.5933 \\
\hline Adjusted pseudo R-squared & 0.3751 & 0.4183 & 0.4820 & 0.5430 & 0.5928 \\
\hline Quasi-LR statistic & $8541.87^{\mathrm{a}}$ & $17154.66^{\mathrm{a}}$ & $30385.04^{\mathrm{a}}$ & $36387.92^{\mathrm{a}}$ & $31711.86^{\mathrm{a}}$ \\
\hline
\end{tabular}

Note $1: \mathrm{a}=\mathrm{p}<0.001 ; \mathrm{b}=\mathrm{p}<0.01 ; \mathrm{c}=\mathrm{p}<0.05$

Note $2: *=$ the quantile estimate is significantly different from the previous quantile estimate (prob<5\%). The Wald statistics for the slope equality tests between quantiles are available upon request. 